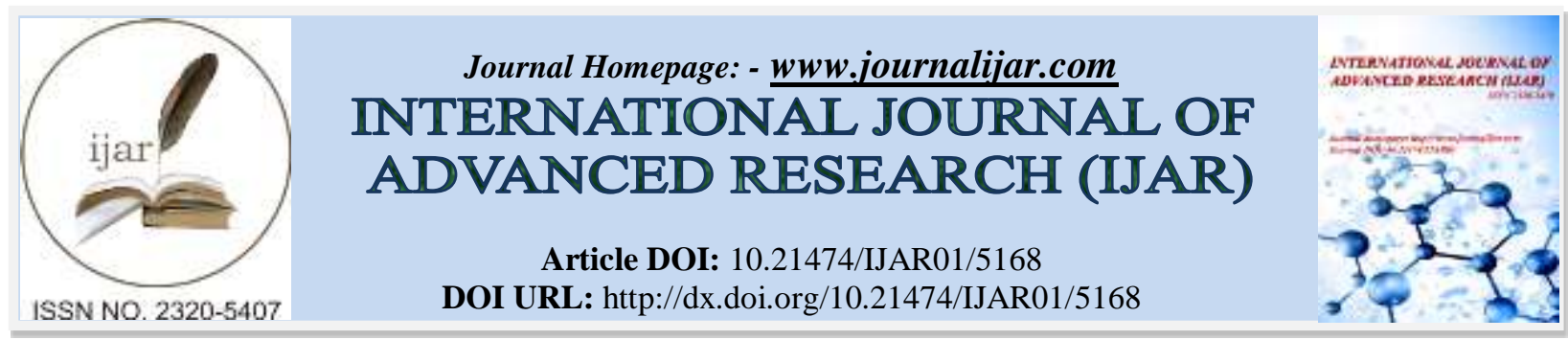

RESEARCH ARTICLE

\title{
TITANIUM-REINFORCED ZIRCONIA ABUTMENTS VERSUS PURE ZIRCONIA ABUTMENTS FOR IMPLANT-SUPPORTED SINGLE TOOTH RESTORATIONS: A SYSTEMATIC REVIEW.
}

\author{
Ahlam A. Othman BDS, MSD ${ }^{1,2}$, Hesham A. Katamish BDS, MSD, $\mathrm{PhD}^{3}$ and Atef Shaker BDS, MSD, PhD ${ }^{4}$. \\ 1. PhD student, Department of Fixed Prosthodontics, Faculty of Oral and Dental Medicine, Cairo University, \\ Egypt. \\ 2. Department of Fixed Prosthodontics, Sana`a University, Sana`a, Yemen. \\ 3. Professor, Department of Fixed Prosthodontics, Former Dean, Faculty of Oral and Dental Medicine, Cairo \\ University, Egypt. \\ 4. Professor, Department of Fixed Prosthodontics, Faculty of Oral and Dental Medicine, Cairo University, Egypt.
}

\section{Manuscript Info}

(...........................

Manuscript History

Received: 14 June 2017

Final Accepted: 16 July 2017

Published: August 2017

Key words:-

Randomized controlled trial, Dental implants, Dental abutments, Zirconia implant abutment.

\section{Abstract}

Statement of problem: Recently, zirconia abutments are widely replacing the gold standard titanium abutments in restoring dental implants especially in aesthetic areas due to their superior aesthetics, excellent biocompatibility and satisfactory mechanical properties. However, excessive hardness of zirconia in comparison to titanium results in wear at implant-abutment interface followed by many technical and aesthetic complications. New zirconia abutments, with titanium component at the apical portion, were developed to overcome these complications and improve their mechanical performance.

Purpose: To compare the effectiveness of titanium-reinforced zirconia abutments versus pure zirconia abutments in patients restored with implant-supported single tooth restorations to improve post-insertion abutment survival and patient satisfaction.

Material and methods: We searched the Cochrane Oral Health Group Trial register (25 December 2016), Cochrane Central Register of Controlled Trials (The Cochrane Library, 2016, Issue 12), MEDLINE (January 1966 to 25 December 2016) and the WHO International Clinical Trial Registry Platform (25 December 2016). We did not apply any language or date restrictions. Inclusion criteria were randomized controlled trials (RCTs) comparing titanium-reinforced zirconia abutments versus pure zirconia abutments in patients restored with implant-supported single tooth restorations. Two review authors independently assessed trials for inclusion. Risk of bias assessment, extracting the data and checking for accuracy were to be conducted by two review authors independently, and the results were to be expressed as risk ratio (RR) or mean differences (MD), together with their $95 \%$ confidence intervals (CI). The primary outcome measures were postinsertion abutment survival and patient satisfaction.

Results: No eligible RCTs were identified for inclusion in the review. Conclusions: There is no evidence to support the use of titaniumreinforced zirconia abutments or pure zirconia abutments in patients 
restored with implant-supported single tooth restorations to improve post-insertion abutment survival and patient satisfaction.

The protocol for this systematic review (One-piece versus twopiece zirconia abutments for implant-supported crowns) was registered on PROSPERO 2017:CRD42017054286 Available from http://www.crd.york.ac.uk/PROSPERO/display_record.asp ?ID=CRD42017054286.

Copy Right, IJAR, 2017,. All rights reserved.

\section{Plain language summary:-}

\section{One-piece versus two-piece zirconia abutments for implant-supported crowns}

In implant restorations, the abutment is the structure that is placed directly on top of the implant, upon which the final crown is cemented. The increased esthetic demands in implant dentistry have led to the development of ceramic abutments, such as zirconia abutments, which are considered to be a good alternative to standard grey titanium abutments due to their white color and their excellent biological and mechanical properties. The majority of zirconia abutments used is made completely of zirconia material i.e. one-piece abutment. Despite their advantages, the excessive hardness of zirconia abutments in comparison to titanium implant results in wear at the surfaces of the abutment and implant facing each other. This leads to several clinical complications including fracture of zirconia abutment, mobility of the abutment due to loosing of its tightening screw, or greyish discoloration of the gums. New two-piece titanium-zirconia abutments were developed to solve these limitations. They are made of two materials: zirconia abutment with a titanium core to face the titanium surface of the implant. This abutment design minimized the incidence of wear with its unfavorable results. The review aimed to find evidence for the effectiveness of twopiece titanium-zirconia abutments versus one-piece zirconia abutments for patients with stand-alone implantsupported crowns. Out of 505 studies, no trials were found, and to date selection of the type of zirconia abutment depends only on data available from other clinical study designs or in vitro studies. Therefore high-quality randomized clinical trials are required to compare these abutment types to determine which is better in terms of abutment longevity and patient satisfaction.

\section{Background:-}

\section{Description of the condition:-}

Titanium abutments are considered to be the gold standard in implant dentistry due to their excellent survival rates and superior biological and mechanical properties. ${ }^{(1)}$ However, the grey color of these abutments results in bluish discoloration of peri-implant mucosa, especially in patients with thin gingival biotype, which in turn compromises mucogingival esthetics. ${ }^{(2)}$

In an attempt to fulfil the esthetic demands of clinicians and patients, ceramic abutments were developed. Nowadays, zirconia (3-yttria stabilized zirconia polycrystals; YTZP) is considered the ceramic material of choice for implant abutments. They are esthetically superior to titanium abutments due to their tooth-colored appearance. They are also characterized by their excellent biocompatibility and superior mechanical properties which are mainly attributed to transformation toughening mechanism of zirconia (ceramic steel). ${ }^{(3),(4),(5)}$

Despite these advantages, zirconia abutments showed more technical complications in comparison to titanium abutments. ${ }^{(6)}$ This has been attributed to many factors including brittleness of zirconium dioxide ceramics ${ }^{(7)}$, difficult machinability of ceramic abutments to the same degree of precision as metallic abutments ${ }^{(8)}$, and different implant/abutment connection designs. ${ }^{(9),(10),(11)}$

Zirconia abutments made of pure zirconium dioxide create direct zirconium/titanium implant-abutment interface. The excessive hardness and higher Young`s modulus of zirconia in comparison to titanium results in fretting wear and deformation of titanium implant platform and hex ${ }^{(12),(13)}$ which in turn leads to several post-insertion complications including fracture of the zirconia abutment, abutment screw loosening, and greyish discoloration of the peri-implant mucosa resulting from the wear titanium particles . ${ }^{(8),(10),(14)}$

\section{Description of the intervention:-}

Titanium-reinforced zirconia abutments are made of both zirconia and titanium resulting in a favorable titanium to titanium implant-abutment interface. They are fabricated in different ways including; 1) a titanium insert (Ti base) 
that is friction-fitted to zirconia abutment. 2) a titanium insert (Ti base) that is bonded to zirconia abutment using resin cement ${ }^{(15)}$ or 3) a titanium collar (sleeve) that is fixed to the apical part of zirconia abutment. These types of abutments are also known as two-piece abutments or hybrid Ti-Zr abutments. ${ }^{(10)}$

\section{How the intervention might work:-}

To overcome the limitations of pure zirconia abutments, titanium-reinforced zirconia abutments were developed. The superior mechanical performance of the titanium-reinforced abutments has been attributed to the presence of titanium interface at the apical part of zirconia abutment which resulted in metal to metal implant-abutment interface. The similarity in physical properties of interfacing materials allows for higher mechanical stability and nullified wear potential. ${ }^{(9),(10),(13),(15),(16)}$ These hybrid Ti-Zr abutments combine good esthetics of zirconia with mechanical advantage of all-titanium implant-abutment interface. ${ }^{(17),(18)}$

\section{Why it is important to do this review:-}

Up to date, there is no consensus on the ideal implant-abutment connection, and with the increased use of ceramic materials to meet the esthetic requirements of the dental patients, the ideal implant-abutment interface design in terms of abutment survival and patient satisfaction should be determined. ${ }^{(5),(6),(10),(19)}$

\section{Objectives:-}

To compare the effectiveness of titanium-reinforced zirconia abutments versus pure zirconia abutments in patients restored with implant-supported single tooth restorations to improve post-insertion abutment survival and patient satisfaction.

\section{Methods:-}

Criteria for considering studies for this review :-

Types of studies:-

Randomized controlled trials (RCTs) including split mouth and cluster randomized trials. We did not include crossover trials or quasi-RCTs.

Types of participants:-

Patients restored with implant-supported single tooth restorations (Both arches, all sites).

\section{Types of interventions:-}

Titanium-reinforced zirconia abutments versus pure zirconia abutments.

Types of outcome measures:-

Primary outcomes:-

1. Post-insertion abutment survival (The abutment is free from any mechanical complications including wear, screw loosening, or fracture).

2. Patient satisfaction using visual analogue scale (VAS).

Secondary outcomes:-

Titanium tattooing of peri-implant soft tissues.

All outcomes will be assessed at the following time intervals:

- Short-term $(<1$ year $)$

- Medium term (1- 5 years)

- Long-term (> 5 years)

Search methods for identification of studies:-

Electronic searches:-

We searched the Cochrane Oral Health Group Trial register (25 December 2016). The Cochrane Oral Health

Group's Trials Register contains trials identified from:

1. Monthly searches of the Cochrane Central Register of Controlled Trials (CENTRAL).

2. Weekly searches of MEDLINE.

3. Weekly searches of Embase.

4. Hand searches of journals and the proceedings of major conferences. (Table 1) 
In addition, we searched CENTRAL (The Cochrane Library, 2016, Issue 12), MEDLINE (January 1966 to 25 December 2016) and the WHO International Clinical Trial Registry Platform (25 December 2016) using the search strategies detailed in Appendix 1.

\section{Searching other resources:-}

We planned to handsearch the citation lists of relevant publications. We did not apply any language or date restrictions.

Data collection and analysis:-

The following methods section of this review is based on a standard template used by the Cochrane Pregnancy and Childbirth Group.

\section{Selection of studies:-}

We assessed for inclusion all potential studies we identified as a result of the search strategy. There was no disagreement regarding the selection of the studies.

\section{Data extraction and management:-}

We did not identify any randomized controlled trials for inclusion in this review. However, if we identify and include any trials in future updates, we will design a form to extract data. For eligible studies, two review authors will extract the data using the agreed form. We will resolve discrepancies through discussion or, if required, we will consult a third person. We will enter data into RevMan Review Manager software ${ }^{(20)}$ and check for accuracy. When information regarding any of the above is unclear, we will attempt to contact authors of the original reports to provide further details.

\section{Assessment of risk of bias in included studies:-}

We did not identify any randomized controlled trials for inclusion in this review. However, if we identify and include any trials in future updates, two review authors will independently assess risk of bias for each study using the criteria outlined in the Cochrane Handbook for Systematic Reviews of Interventions. ${ }^{(21)}$ We will resolve any disagreement by discussion or by involving a third assessor.

\section{(1) Random sequence generation (checking for possible selection bias):-}

We will describe for each included study the method used to generate the allocation sequence in sufficient detail to allow an assessment of whether it should produce comparable groups. We will assess the method as:

- Low risk of bias (any truly random process, e.g. random number table; computer random number generator).

- Unclear risk of bias.

\section{(2) Allocation concealment (checking for possible selection bias):-}

We will describe for each included study the method used to conceal allocation to interventions prior to assignment and assess whether intervention allocation could have been foreseen in advance of, or during recruitment, or changed after assignment. We will assess the methods as:

- Low risk of bias (e.g. telephone or central randomization; consecutively numbered sealed opaque envelopes).

- High risk of bias (open random allocation; unsealed or non-opaque envelopes).

- Unclear risk of bias.

\section{(3) Blinding:-}

(3.1) Blinding of participants and personnel (checking for possible performance bias):-

We will describe for each included study the methods used, if any, to blind study participants and personnel from knowledge of which intervention a participant received.

We will consider studies to be at low risk of bias if they were blinded, or if we judge that the lack of blinding would be unlikely to affect results. We will assess blinding separately for different outcomes or classes of outcomes. We will assess the methods as:

- Low, high or unclear risk of bias for participants and for personnel.

\section{(3.2) Blinding of outcome assessment (checking for possible detection bias):-}

We will describe for each included study the methods used, if any, to blind outcome assessors from knowledge of which intervention a participant received. We will assess blinding separately for different outcomes or classes of 
outcomes.

We will assess the methods used to blind outcome assessment as:

- Low, high or unclear risk of bias.

(4) Incomplete outcome data (checking for possible attrition bias due to the amount, nature and handling of incomplete outcome data):-

We will describe for each included study, and for each outcome or class of outcomes, the completeness of data including attrition and exclusions from the analysis. We will state whether attrition and exclusions were reported and the numbers included in the analysis at each stage (compared with the total randomized participants), reasons for attrition or exclusion were reported, and whether missing data were balanced across groups or were related to outcomes. Where sufficient information is reported, or can be supplied by the trial authors, we will re-include missing data in the analyses which we undertake. We will assess methods as:

1. Low risk of bias (e.g. no missing outcome data; missing outcome data balanced across groups).

2. High risk of bias (e.g. numbers or reasons for missing data imbalanced across groups 'as treated' analysis done with substantial departure of intervention received from that assigned at randomization), we will consider a $20 \%$ or more loss of participants as high risk of bias.

3. Unclear risk of bias.

\section{(5) Selective reporting (checking for reporting bias):-}

We will assess the methods as:

1. Low risk of bias (where it is clear that all of the study's pre-specified outcomes and all expected outcomes of interest to the review have been reported).

2. High risk of bias (where not all the study's pre-specified outcomes have been reported; one or more reported primary outcomes were not pre-specified; outcomes of interest are reported incompletely and so cannot be used; study fails to include results of a key outcome that would have been expected to have been reported).

3. Unclear risk of bias.

(6) Other bias (checking for bias due to problems not covered by (1) to (5) above):-

we will describe for each included study any important concerns we have about other possible sources of bias.

[Note: Concerns about bias could include for example, was there a potential source of bias related to the specific study design? Was the trial stopped early due to some data-dependent process? Was there extreme baseline imbalance? Has the study been claimed to be fraudulent?]

We will assess whether each study was free of other problems that could put it at risk of bias:

1. Low risk of other bias.

2. High risk of other bias.

3. Unclear whether there is risk of other bias.

\section{(7) Overall risk of bias: -}

With reference to (1) to (6) above, we will assess the likely magnitude and direction of the bias and whether we consider it is likely to impact on the findings. We will explore the impact of the level of bias through undertaking sensitivity analyses.

\section{Measures of treatment effect:-}

We planned to carry out statistical analysis using Review Manager software ${ }^{(20)}$. We planned to use aggregate data from the included studies.

Dichotomous data: -

For dichotomous data, we will present results as summary risk ratio with $95 \%$ CI.

Continuous data:-

For continuous data, we will use the mean difference with $95 \% \mathrm{CI}$.

Unit of analysis issues:-

The statistical unit is the abutment. 


\section{Cluster-randomized trials:-}

We did not identify any cluster-randomized trials for inclusion in this review. However, if we identify any clusterrandomized trials in future updates, we will include them in the analyses along with individually randomized trials. We will adjust their sample sizes using the methods described in the Cochrane Handbook for Systematic Reviews of Interventions ${ }^{(21)}$, using an estimate of the intracluster correlation co-efficient (ICC) derived from the trial (if possible), from a similar trial or from a study of a similar population. If we use ICCs from other sources, we will report this and conduct sensitivity analyses to investigate the effect of variation in the ICC. If we identify both cluster-randomized trials and individually-randomized trials, we plan to synthesize the relevant information. We will consider it reasonable to combine the results from both if there is little heterogeneity between the study designs and the interaction between the effect of intervention and the choice of randomization unit is considered to be unlikely. We will also acknowledge heterogeneity in the randomization unit and perform a subgroup analysis to investigate the effects of the randomization unit.

\section{Dealing with missing data:-}

In future updates, if we identify and include any trials, we will note levels of attrition for included studies. We plan to explore the impact of including studies with high levels of missing data in the overall assessment of treatment effect by using sensitivity analysis. For all outcomes, we will carry out analyses, as far as possible, on an intentionto-treat basis, i.e. we will include all participants randomized to each group in the analyses, and analyze all participants in the group to which they were allocated, regardless of whether or not they received the allocated intervention. The denominator for each outcome in each trial will be the number randomized minus any participants whose outcomes will be known to be missing.

\section{Assessment of heterogeneity:-}

In future updates, if we identify and include any trials, we will assess statistical heterogeneity in each meta-analysis using the $\mathrm{T}^{2}, \mathrm{I}^{2}$ and $\mathrm{Chi}^{2}$ statistics. We will consider heterogeneity as substantial if $\mathrm{I}^{2}$ was greater than $30 \%$ and either $\mathrm{T}^{2}$ was greater than zero, or there was a low $\mathrm{P}$ value (less than 0.10 ) in the $\mathrm{Chi}^{2}$ test for heterogeneity.

\section{Assessment of reporting biases:-}

In future updates of this review, if there are 10 or more studies in the meta-analysis we will investigate reporting biases (such as publication bias) using funnel plots. We will assess funnel plot asymmetry visually. If asymmetry is suggested by a visual assessment, we will perform exploratory analyses to investigate it.

\section{Data synthesis:-}

In future updates, if we identify and include any trials, we will use fixed-effect meta-analysis for combining data where it is reasonable to assume that studies are estimating the same underlying treatment effect: i.e. where trials are examining the same intervention, and the trials' populations and methods are judged sufficiently similar. If there is clinical heterogeneity sufficient to expect that the underlying treatment effects differ between trials, or if substantial statistical heterogeneity is detected, we will use random-effects meta-analysis to produce an overall summary if an average treatment effect across trials is considered clinically meaningful. The random-effects summary will be treated as the average of the range of possible treatment effects and we will discuss the clinical implications of treatment effects differing between trials. If the average treatment effect is not clinically meaningful we will not combine trials. If we use random-effects analyses, the results will be presented as the average treatment effect with 95\% confidence intervals, and the estimates of Tau-squared and I-squared.

\section{Subgroup analysis and investigation of heterogeneity:-}

In future updates, if there are included trials and data is available, and we identified substantial heterogeneity, we will investigate it using subgroup analyses and sensitivity analyses. We will consider whether an overall summary is meaningful, and if it is, use random-effects analysis to produce it.

We will conduct subgroup analysis by the implant-supported restoration site (anterior versus posterior restorations). We plan to conduct this subgroup analysis for the primary outcomes. We will assess subgroup differences by interaction tests available within RevMan. ${ }^{(20)}$. We will report the results of subgroup analyses quoting the $\mathrm{Chi}^{2}$ statistic and $\mathrm{P}$ value, and the interaction test $\mathrm{I}^{2}$ value. 


\section{Sensitivity analysis:-}

In future updates, if we identify and include any trials, we will carry out sensitivity analysis to explore the effects of trial quality assessed by omitting studies rated as high risk of bias and unclear when considering allocation concealment and incomplete outcome data. We plan to conduct sensitivity analysis by omitting cluster randomized trials. We plan to restrict this to the primary outcomes.

\section{Results:-}

Description of studies:-

We did not identify any eligible or potentially eligible studies for inclusion.

Results of the search:-

The detailed search results are depicted in PRISMA flow diagram ${ }^{(22)}$ (Figure 1).

Included studies:-

There were no studies eligible for inclusion in the review.

Excluded studies:-

All studies were excluded through title and abstract screening, and none required full text retrieval for assessment.

Risk of bias in included studies:-

There were no eligible studies for inclusion.

\section{Allocation (selection bias):-}

There were no eligible studies for inclusion.

Blinding (performance bias and detection bias):-

There were no eligible studies for inclusion.

Incomplete outcome data (attrition bias):-

There were no eligible studies for inclusion.

Selective reporting (reporting bias):-

There were no eligible studies for inclusion.

Other potential sources of bias:-

There were no eligible studies for inclusion.

Effects of interventions:-

No data was available for analysis because no relevant studies were identified.

\section{Discussion:-}

Summary of main results:-

We did not find any RCTs comparing titanium-reinforced zirconia abutments versus pure zirconia abutments in patients restored with implant-supported single tooth restorations. The studies identified were of other methodologies such as retrospective studies, case series, case reports and in vitro studies.

\section{Overall completeness and applicability of evidence:-}

No RCTs were identified to answer our review question, and the review is complete within the scope of our comparison; titanium-reinforced zirconia abutments versus pure zirconia abutments in patients restored with implant-supported single tooth restorations. However, this lack of RCTs could be attributed to the narrow scope of the review, since RCTs were found comparing other types of implant abutments. Baldini et al ${ }^{(23)}$; Cosgarea et al ${ }^{(24)}$ ; Carrillo de Albornoz et al ${ }^{(25)}$; Ferrari et al ${ }^{(26),(27)}$; Sailer et al ${ }^{(28)}$; Zembic et al ${ }^{(29),(30)}$, compared different types of titanium abutments versus zirconia; while others compared between the different types of zirconia abutments: Büchi et al ${ }^{(31)}$ and Thoma et al ${ }^{(32)}$ compared the veneered zirconia versus white zirconia; Paolantoni et al ${ }^{(33)}$ compared one-piece versus two-piece custom made zirconia anchorages and final prosthetic restoration; and Schepke et $\mathrm{al}^{(34)}$ reported the comparison between stock versus customized zirconia.

\section{Quality of the evidence:-}

No eligible studies were identified to allow a robust conclusion on the effectiveness of titanium-reinforced zirconia abutments in comparison to pure zirconia abutments in patients restored with implant-supported single tooth restorations to improve post-insertion abutment survival and patient satisfaction. The evidence currently available is obtained from low quality studies that should not be used to inform or guide the clinicians through their practice. However, this data can be used to generate hypotheses for future high quality RCTs. 


\section{Potential biases in the review process:-}

We performed comprehensive search in more than one electronic database. We did not apply any language or date restrictions. Two review authors screened the search results and assessed eligibility for inclusion in the review. Thus, we are not concerned that any bias could have affected our search process or screening of the studies, and since no relevant studies were identified; no data collection, risk of bias assessment, or analysis were performed.

\section{Agreements and disagreements with other studies or reviews:-}

No systematic reviews or RCTs were found comparing titanium-reinforced zirconia abutments with pure zirconia abutments in patients restored with implant-supported single tooth restorations. However, others have used data from study designs that provide low quality evidence (Brodbeck ${ }^{(8)}$;Canullo ${ }^{(35)}$; Fabbri $^{(36)}$; Stimmelmayr $2012^{(16)}$ ) to inform the practice. They reported superior performance of the titanium-reinforced zirconia abutments regarding survival rate, fracture strength, esthetics, and absence of mechanical or biological complications. This was attributed to the presence of secondary titanium insert that substituted the weakest part of one-piece zirconia abutment and reinforced its mechanical properties. In addition, titanium tattooing of the gingival tissue that results from wear at implant-abutment interface in pure zirconia abutments (37) was not reported in cases restored with two-pieces titanium zirconia abutments.

Authors' conclusions:-

Implications for practice:-

There is no evidence to support the use of titanium-reinforced zirconia abutments or pure zirconia abutments in patients restored with implant-supported single tooth restorations to improve post-insertion abutment survival.

\section{Implications for research:-}

Well designed and properly conducted high-quality randomized controlled trials are required to compare between the effectiveness of titanium-reinforced zirconia abutments and pure zirconia abutments with regards to postinsertion abutment survival and patient satisfaction. The trials should assess and report these outcomes after clinically meaningful follow up periods, should avoid surrogate outcomes, and should be reported as recommended by the CONSORT statement (www.consort-statement.org).

\section{Contributions of authors:-}

Ahlam A. Othman (AAO), Hesham A. Katamish (HAK), Atef Shaker (AS)

Conceiving the review: AAO, HAK, AS

Coordinating the review: AAO, HAK

Undertaking manual searches: AAO, AS

Screening search results: AAO, AS

Writing the review: AAO

Person responsible for reading and checking review before submission: AAO

\section{Declarations of interest; none.}

\section{Collaborators:}

Professor Ashraf Nabhan, Ain Shams University.

Dr. Marwah Anas El-Wegoud, MSA University.

Table 1:- Journal Handsearching Programme

\begin{tabular}{|l|l|l|l|}
\hline Journal title & Years being searched & Years completed & $\begin{array}{l}\text { Prospective search } \\
\text { (y/n) }\end{array}$ \\
\hline Acta Odontologica Scandinavica & 1948 -onwards & $1965-2002$ & $\begin{array}{l}\text { Y (retrospective } \\
\text { search stopped due to } \\
\text { poor yield) }\end{array}$ \\
\hline American Dental Association Jnl (JADA) & 1948 -onwards & $1953-2003$ & Y \\
\hline American Journal of Dentistry & 1988 -onwards & $1988-2003$ & - \\
\hline $\begin{array}{l}\text { American Journal of Orthodontics } \\
\text { (became Am-J-Orthod \& Dentofacial } \\
\text { Ortho in 1986) }\end{array}$ & $1970-1985$ & - & - \\
\hline
\end{tabular}




\begin{tabular}{|c|c|c|c|}
\hline $\begin{array}{l}\text { American Journal of Orthodontics \& } \\
\text { Dentofacial Orthopedics }\end{array}$ & 1986-onwards & $1986-2004$ & $\mathrm{Y}$ \\
\hline Angle Orthodontist & 1948-onwards & $1979-2003$ & $\mathrm{Y}$ \\
\hline \multicolumn{4}{|l|}{ Archives of Oral Biology } \\
\hline ASDC - J-Dentistry for Children & 1948-onwards & 1964-2002 & $\mathrm{Y}$ \\
\hline Australian Dental Journal & 1956-onwards & 1956-1996, 2003 & $\mathrm{Y}$ \\
\hline Australian Orthodontic Journal & 1981-onwards & 1981-1986, 2002 & $\mathrm{Y}$ \\
\hline Brazilian Journal of Oral Sciences & $\begin{array}{l}\text { 2002-2004 (searched } \\
\text { electronically) }\end{array}$ & - & - \\
\hline British Dental Journal & 1948-onwards & $1958-2004$ & $\begin{array}{l}Y \text { (retrospective } \\
\text { search stopped due to } \\
\text { poor yield) }\end{array}$ \\
\hline British Journal of Cancer & 1997-1999 & - & - \\
\hline British Journal of Oral Surgery & 1963-1983 & - & - \\
\hline $\begin{array}{l}\text { British Journal of Oral \& Maxillofacial } \\
\text { Surgery }\end{array}$ & $\begin{array}{l}1984,1988-1993,1999- \\
2003\end{array}$ & - & $\mathrm{Y}$ \\
\hline (British) Journal of Orthodontics & 1973-onwards & 1973-2004 & $\mathrm{Y}$ \\
\hline British Journal of Plastic Surgery & 1986-1987, 1989-2001 & - & $\mathrm{Y}$ \\
\hline Caries Research & 1967-onwards & $1967-2003$ & $\mathrm{Y}$ \\
\hline $\begin{array}{l}\text { Cleft Palate Journal (became Cleft Palate } \\
\text { Craniofacial Journal from 1991) }\end{array}$ & $1964-1990$ & - & - \\
\hline Cleft Palate Craniofacial Journal & 1991-onwards & - & - \\
\hline $\begin{array}{l}\text { Clinical Implant Dentistry and Related } \\
\text { Research }\end{array}$ & 1999-onwards & $1999-2002$ & $\mathrm{Y}$ \\
\hline Clinical Oral Implants Research & 1990-onwards & 1990-2000, 2002 & $\mathrm{Y}$ \\
\hline Clinical Oral Investigations & 1997-onwards & $1997-2003$ & $\mathrm{Y}$ \\
\hline $\begin{array}{l}\text { Clinical Orthodontics and Research } \\
\text { (became Orthodontics \& Craniofacial } \\
\text { Research from 2002) }\end{array}$ & $1998-2001$ & - & $\mathrm{Y}$ \\
\hline Community Dental Health & 1984-onwards & 1984-2002 & $\mathrm{Y}$ \\
\hline $\begin{array}{l}\text { Community Dentistry \& Oral } \\
\text { Epidemiology }\end{array}$ & 1973-onwards & $1973-2001$ & $\mathrm{Y}$ \\
\hline $\begin{array}{l}\text { Compendium of Continuing Education in } \\
\text { Dentistry }\end{array}$ & 1980-onwards & $1983-2002$ & - \\
\hline $\begin{array}{l}\text { European Journal of Oral Sciences } \\
\text { (formerly Scandinavian Journal of Dental } \\
\text { Research (1970-1994)) }\end{array}$ & 1995-onwards & $\begin{array}{l}1995-1996,2002- \\
2003\end{array}$ & - \\
\hline European Journal of Orthodontics & 1979-onwards & 1979-2004 & $\mathrm{Y}$ \\
\hline European Jnl of Paediatric Dentistry & 2000-onwards & $2000-2002$ & $\mathrm{Y}$ \\
\hline Implant Dentistry & 1992-onwards & $1992-2003$ & $\mathrm{Y}$ \\
\hline $\begin{array}{l}\text { Implantologist (later title Implant } \\
\text { Dentistry) }\end{array}$ & $(1976-1987)$ & - & $\begin{array}{l}\text { Not searched due to } \\
\text { poor yield }\end{array}$ \\
\hline International Dental Journal & 1950-onwards & $1967,1970-2001$ & $\begin{array}{l}\text { Y (retrospective } \\
\text { search stopped due to } \\
\text { poor yield) }\end{array}$ \\
\hline Int-J-Computerized Dentistry & 1998-onwards & 1998-2001 & Discontinued \\
\hline $\begin{array}{l}\text { Int-J-Oral Implantology (became Implant } \\
\text { Dentistry) (former title Implantologist) }\end{array}$ & 1988-1991 & 1988-1991 & $\mathrm{N}$ \\
\hline Int-J-Oral \& Maxillofacial Implants & 1986-onwards & $1986-2003$ & $\mathrm{Y}$ \\
\hline $\begin{array}{l}\text { Int-J-Oral Surgery (became Int-J-Oral \& } \\
\text { Maxfac-Surg 1986) }\end{array}$ & $1972-1985$ & $1972-1985$ & - \\
\hline $\begin{array}{l}\text { Int-J-Oral \& Maxillofacial Surgery } \\
\text { (formerly Int-J-Oral-Surg) }\end{array}$ & $1972-1993$ & $1986-2001$ & $\mathrm{Y}$ \\
\hline Int-J-Pediatric Otorhinolaryngology & 1979-onwards & $1997-2001$ & $\mathrm{Y}$ \\
\hline
\end{tabular}




\begin{tabular}{|c|c|c|c|}
\hline Int-J-Paediatric Dentistry & 1971-onwards & 1991-2004 & $\mathrm{Y}$ \\
\hline Int-J-Prosthodontics & 1988-onwards & $1988-2000$ & $\mathrm{Y}$ \\
\hline Journal Clinical Dentistry & 1988-onwards & 1988-2002 & $\mathrm{Y}$ \\
\hline Journal Clinical Orthodontics & 1967-onwards & $1970-1990$ & $\mathrm{Y}$ \\
\hline J-Clin-Pediatric Dentistry & 1990-onwards & $1996-2003$ & - \\
\hline Journal Clinical Periodontology & 1974-onwards & $1974-2003$ & $\mathrm{Y}$ \\
\hline J-Cranio-Maxillofacial Surgery & 1991-onwards & $2001-2003$ & $\mathrm{Y}$ \\
\hline Journal of Dental Research & 1948-onwards & $\begin{array}{l}1964-1967,1968- \\
1969,1971-1974, \\
1976-2003\end{array}$ & $\mathrm{Y}$ \\
\hline Journal of Dentistry & 1972 & $1972-2003$ & $\mathrm{Y}$ \\
\hline Journal of Endodontics & 1996-onwards & $1997-2002$ & $\mathrm{Y}$ \\
\hline $\begin{array}{l}\text { J-Oral Implantology (formerly Oral } \\
\text { Implantology) }\end{array}$ & 1978-onwards & $\begin{array}{l}1978-1981,1986- \\
2000\end{array}$ & Y \\
\hline Journal of Oral Rehabilitation & 1974-onwards & $1992-2003$ & $\mathrm{Y}$ \\
\hline $\begin{array}{l}\text { Journal of Oral Surgery/Journal of Oral \& } \\
\text { Maxillofacial Surgery (formerly Journal of } \\
\text { Oral Surgery, Anesthetics \& Hospital } \\
\text { Dental Service) }\end{array}$ & $1968-2002$ & - & $\mathrm{Y}$ \\
\hline $\begin{array}{l}\text { Journal of Oral Surgery, Anesthetics \& } \\
\text { Hospital Dental Service }\end{array}$ & $1962-1963$ & - & $\mathrm{Y}$ \\
\hline Journal of Orthodontics & $2000-2004$ & - & $\mathrm{Y}$ \\
\hline Journal of Pediatric Dentistry & $1985-1990$ & - & - \\
\hline Journal of Periodontal Research & 1966-onwards & $\begin{array}{l}1966-1999,2002- \\
2003\end{array}$ & $\mathrm{Y}$ \\
\hline Journal of Periodontology & 1948-onwards & $1953-2003$ & $\mathrm{Y}$ \\
\hline Journal of Prosthetic Dentistry & 1951-onwards & $\begin{array}{l}\text { 1964, 1970-1976, } \\
1978-1984,1990- \\
1998\end{array}$ & $\mathrm{Y}$ \\
\hline Journal of Prosthodontics & 1992-onwards & 1993-2000 & $\mathrm{Y}$ \\
\hline Journal of Public Health Dentistry & $1997-2003$ & - & - \\
\hline $\begin{array}{l}\text { Odontologisk Revy (merged with Swedish } \\
\text { Dental Journal) }\end{array}$ & $1950-1976$ & $1969,1973-1974$ & $\begin{array}{l}\text { Search cancelled due } \\
\text { to poor yield }\end{array}$ \\
\hline Operative Dentistry & 1976-onwards & $1983-2002$ & $\mathrm{Y}$ \\
\hline Oral Implantology & $1970-1977$ & - & $\begin{array}{l}\text { Search cancelled due } \\
\text { to poor yield }\end{array}$ \\
\hline $\begin{array}{l}\text { Oral Surgery, Oral Medicine, Oral } \\
\text { Pathology }\end{array}$ & 1948-onwards & $1948-2003$ & $\mathrm{Y}$ \\
\hline $\begin{array}{l}\text { Orthodontics \& Craniofacial Research } \\
\text { (formerly Clinical Orthodontics \& } \\
\text { Research) }\end{array}$ & $2002-2003$ & - & $\mathrm{Y}$ \\
\hline Paediatric Dentistry & 1979-onwards & $1995-2001$ & $\mathrm{Y}$ \\
\hline Plastic \& Reconstructive Surgery & 1966-onwards & - & $\mathrm{Y}$ \\
\hline Primary Dental Care & 1994-onwards & 1994-1997 & $\mathrm{Y}$ \\
\hline Progress in Orthodontics & 2000-onwards & 2001 & $\mathrm{Y}$ \\
\hline Quintessence International & 1970-onwards & $1996-2001$ & $\mathrm{Y}$ \\
\hline $\begin{array}{l}\text { Scandinavian Journal of Dental Research } \\
\text { (became European Journal of Oral } \\
\text { Sciences 1995) }\end{array}$ & $1970-1994$ & 1970,1984 & $\mathrm{Y}$ \\
\hline Seminars in Orthodontics & 1995-2001 & - & Poor yield \\
\hline Swedish Dental Journal & $\begin{array}{l}\text { (Nordic Cochrane } \\
\text { Centre searched 1977- } \\
\text { 1995) }\end{array}$ & 1975-1976, 1996 & $\mathrm{Y}$ \\
\hline
\end{tabular}


Figure 1:- PRISMA flow diagram
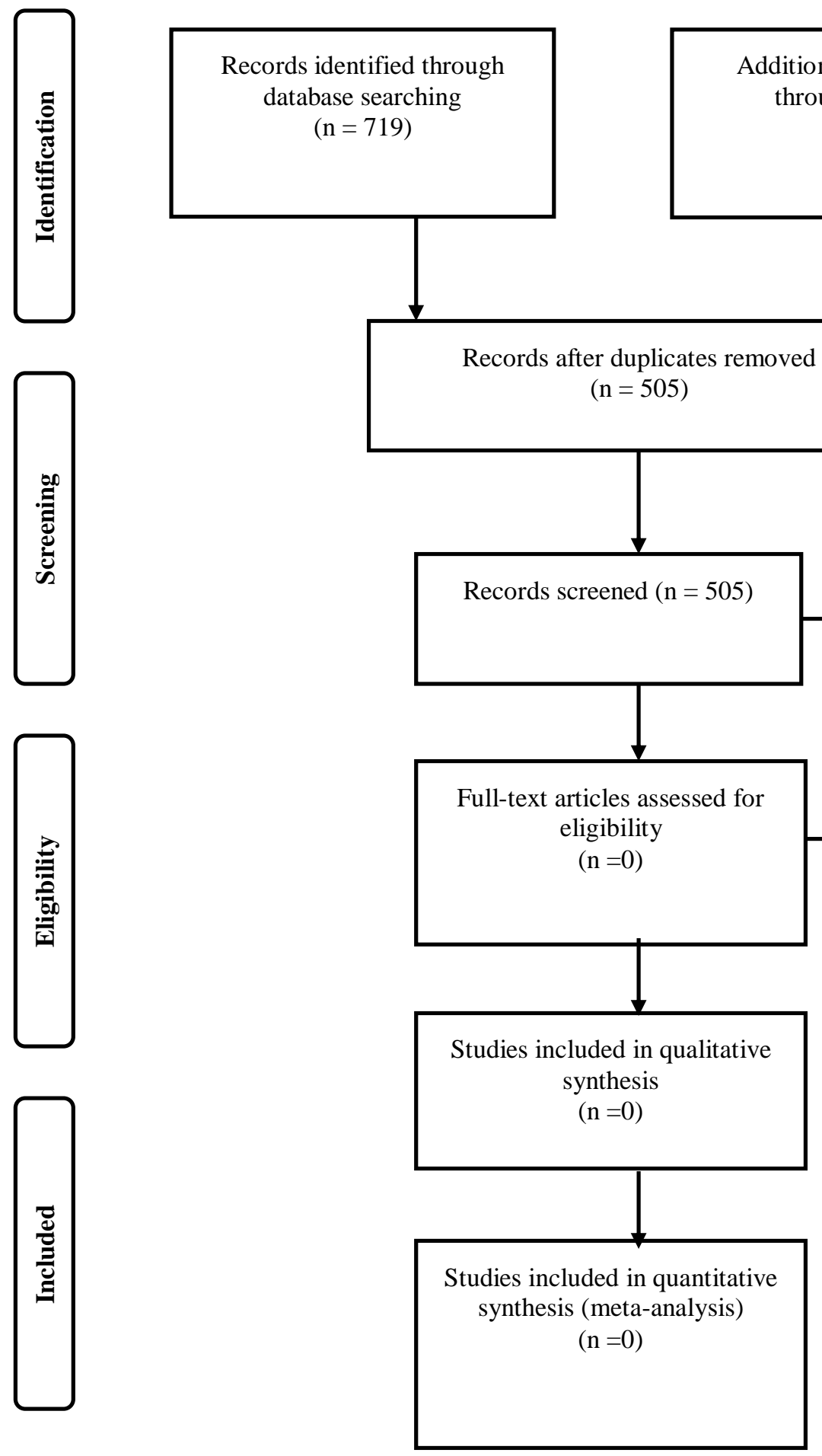

Records excluded

$(\mathrm{n}=505)$

Full-text articles excluded, with reasons $(\mathrm{n}=0)$ 
Appendix 1:- Search strategy

randomized controlled trial[Publication Type] OR

controlled clinical trial[Publication Type] OR

randomized[Title/Abstract] OR

randomly[Title/Abstract] OR

trial[Title/Abstract] OR

groups[Title/Abstract] NOT

animals[MeSH Terms] NOT humans[MeSH Terms]

AND

Dental Implants[MeSH Terms:noexp]) OR

Dental Implant*[Title/Abstract]

AND

Dental Abutments [MeSH Terms] OR

Ceramics [MeSH Terms] OR

Dental Abutments [Title/Abstract] OR

Ceramics [Title/Abstract] OR

Zirconium implant abutment [Title/Abstract] OR

Zirconia abutments [Title/Abstract]

Note: The language of the search strategy was adapted to each of the searched databases regarding field tags and

combination of terms.

\section{References:-}

1. Sailer I, Philipp A, Zembic A, Pjetursson BE, Hämmerle CHF, Zwahlen M. A systematic review of the performance of ceramic and metal implant abutments supporting fixed implant reconstructions. Clin Oral Implants Res. 2009 Sep;20:4-31.

2. Sailer I, Pjetursson BE, Zwahlen M HC. A systematic review of the survival and complication rates of all-ceramic and metal - ceramic reconstructions after an observation period of at least 3 years . Part II : fixed dental prostheses. 2007;86-96.

3. Garvie RC, Hannink RH PR. Ceramic steel? Nature. 1975 Dec 25;258:703-4.

4. Att W, Kurun S, Gerds T, Strub JR. Fracture resistance of single-tooth implant-supported all-ceramic restorations after exposure to the artificial mouth. J Oral Rehabil. 2006;33(5):380-6.

5. Nakamura K, Kanno T, Milleding P, Ortengren U. Zirconia as a dental implant abutment material: a systematic review. Int J Prosthodont. 2010;23(4):299-309.

6. Bidra A Rungruanganunt P Clinical Outcomes of Implant Abutments in the Anterior Region : A Systematic Review. J Esthet Restor Dent. 2013;25(3):159-76.

7. Gehrke P, Dhom G, Brunner J, Wolf D, Degidi M, Piattelli A. Zirconium implant abutments: fracture strength and influence of cyclic loading on retaining-screw loosening. Quintessence Int. 2006;37(1):19-26.

8. rodbeck U. The ZiReal Post: A new ceramic implant abutment. J Esthet Restor Dent. 2003;15(1):10-23.

9. Sailer I, Sailer T, Stawarczyk B, Jung RE, Hämmerle CHF. In vitro study of the influence of the type of connection on the fracture load of zirconia abutments with internal and external implant-abutment connections. Int $\mathrm{J}$ Oral Maxillofac Implants.2009;24(5):850-8.

10. Truninger TC, Stawarczyk B, Leutert CR, Sailer TR, Hämmerle CHF, Sailer I. Bending moments of zirconia and titanium abutments with internal and external implant-abutment connections after aging and chewing simulation. Clin Oral Implants Res. 2012;23(1):12-8.

11. Chun HJ, Yeo IS, Lee JH, Kim SK, Heo SJ, Koak JY, Han JS LS. Fracture strength study of internally connected zirconia abutments reinforced with titanium inserts. Int J Oral Maxillofac Implant. 2015;30(2):346-50.

12. Cavusoglu Y, Akça K. A Pilot Study of Joint Stability at the Zirconium or Titanium Abutment / Titanium Implant Interface. 2014;29(2).

13. Stimmelmayr M, Edelhoff D, Güth JF, Erdelt K, Happe A, Beuer F. Wear at the titanium-titanium and the titaniumzirconia implant-abutment interface: A comparative in vitro study. Dent Mater. 2012;28(12):1215-20.

14. Goodacre CJ, Bernal G, Rungcharassaeng K, Kan JYK. Clinical complications with implants and implant prostheses. J Prosthet Dent. 2003;90(2):121-32.

15. Kim JS, Raigrodski AJ, Flinn BD, Rubenstein JE, Chung KH, Mancl LA. In vitro assessment of three types of zirconia implant abutments under static load. J Prosthet Dent. 2013;109(4):255-63.

16. Stimmelmayr M, Sagerer S, Erdelt K, Beuer F. In vitro fatigue and fracture strength testing of one-piece zirconia implant abutments and zirconia implant abutments connected to titanium cores. Int J Oral Maxillofac Implant. 2013;28(2):488-93. 
17. Gehrke P, Johannson D, Fischer C, Stawarczyk B, Beuer F. In Vitro Fatigue and Fracture Resistance of One- and Two-Piece CAD/CAM Zirconia Implant Abutments. Int J Oral Maxillofac Implant. 2015;30(3):546-54.

18. Carvalho MA, Sotto-Maior BS, Del Bel Cury AA, Pessanha Henriques GE. Effect of platform connection and abutment material on stress distribution in single anterior implant-supported restorations: A nonlinear 3-dimensional finite element analysis. J Prosthet Dent. 2014;112(5):1096-102.

19. Zembic A, Kim S, Zwahlen M, Kelly JR. Systematic review of the survival rate and incidence of biologic, technical, and esthetic complications of single implant abutments supporting fixed prostheses. Int J Oral Maxillofac Implants. 2014;29 Suppl:99-116.

20. Review Manager (RevMan) [Computer program]. Version 5.3. Copenhagen: The Nordic Cochrane Centre, The Cochrane Collaboration, 2014.

21. Higgins JPT GS (editors). Cochrane Handbook for Systematic Reviews of Interventions Version 5.1.0 [updated March 2011]. The Cochrane Collaboration, 2011. Available from http://handbook.cochrane.org. 2011.

22. Moher D, Liberati A, Tetzlaff J, Altman DG TPG. Preferred reporting items for systematic reviews and metaanalyses: the PRISMA statement. Int J Surg. 2010;8(5):336-41.

23. Baldini N, D’Elia C, Clementini M, Carrillo de Albornoz A, Sanz M DSM. Esthetic Outcomes of Single-Tooth Implant-Supported Restorations Using Metal-Ceramic Restorations with Zirconia or Titanium Abutments: A Randomized Controlled Clinical Study. Int J Periodontics Restor Dent. 2016;36(4):59-66.

24. Cosgarea R1, Gasparik C, Dudea D, Culic B, Dannewitz B SA. Peri-implant soft tissue colour around titanium and zirconia abutments : a prospective randomized controlled clinical study. Clin Oral Implant Res. 2015;26(5):537-44.

25. Carrillo de Albornoz A, Vignoletti F, Ferrantino L, Cárdenas E, De Sanctis M SM. A randomized trial on the aesthetic outcomes of implant- supported restorations with zirconia or titanium abutments. J Clin Periodontol. 2014;41(12):1161-0.

26. Ferrari M, Cagidiaco MC, Garcia-Godoy F, Goracci C CF. Effect of different prosthetic abutments on peri-implant soft tissue . A randomized controlled clinical trial. Am J Dent. 2015;28(2):85-9.

27. Ferrari M, Tricarico MG, Cagidiaco MC, Vichi A, Gherlone EF, Zarone F SR. 3-Year Randomized Controlled Prospective Clinical Trial on Different CAD-CAM Implant Abutments. Clin Implant Dent Relat Res. 2016;18(6):1134-41.

28. Sailer I, Zembic A, Jung RE, Siegenthaler D, Holderegger C, Hämmerle CHF. Randomized controlled clinical trial of customized zirconia and titanium implant abutments for canine and posterior single-tooth implant reconstructions: preliminary results at 1 year of function. Clin Oral Implants Res. 2009 Mar;20(3):219-25.

29. Zembic A, Sailer I, Jung RE, Hämmerle CHF. Randomized-controlled clinical trial of customized zirconia and titanium implant abutments for single-tooth implants in canine and posterior regions: 3-year results. Clin Oral Implants Res. 2009;20(8):802-8.

30. Zembic A, Bösch A, Jung RE, Hämmerle CHF, Sailer I. Five-year results of a randomized controlled clinical trial comparing zirconia and titanium abutments supporting single-implant crowns in canine and posterior regions. Clin Oral Implants Res. 2013;24(4):384-90.

31. Büchi DL, Sailer I, Fehmer V, Hämmerle CH TD. All-Ceramic Single-Tooth Implant Reconstructions Using Modified Zirconia Abutments : A Prospective Randomized Controlled Clinical Trial of the Effect of Pink Veneering Ceramic on the Esthetic Outcomes. Int J Periodontics Restor Dent. 2014;34(1):29-37.

32. Thoma DS, Brandenberg F, Fehmer V, Büchi DL, Hämmerle CH SI. Randomized Controlled Clinical Trial of AllCeramic Single Tooth Implant Reconstructions Using Modified Zirconia Abutments : Radiographic and Prosthetic Results at 1 Year of Loading. Clin Implant Dent Relat Res. 2016;18(3):462-72.

33. Paolantoni G, Marenzi G, Blasi A, Mignogna J, Sammartino G. Findings of a Four-Year Randomized Controlled Clinical Trial Comparing Two-Piece and One-Piece Zirconia Abutments Supporting Single Prosthetic Restorations in Maxillary Anterior Region. Biomed Res Int. 2016;2016:8767845.

34. Schepke U, Meijer HJ, Kerdijk W, Raghoebar GM CM. Stock Versus CAD / CAM Customized Zirconia Implant Abutments - Clinical and Patient-Based Outcomes in a Randomized Controlled Clinical. Clin Implant Dent Relat Res. 2016;19(1):74-84.

35. Canullo L. Clinical outcome study of customized zirconia abutments for single-implant restorations. Int $\mathbf{J}$ Prosthodont. 2007;20(5):489-93.

36. Fabbri G, Fradeani M, Dellificorelli G, De Lorenzi M, Zarone F SR. Clinical Evaluation of the Influence of Connection Type and Restoration Height on the Reliability of Zirconia Abutments : A Retrospective Study on 965 Abutments with a Mean 6-Year Follow-Up. Int J Periodontics Restor Dent. 2017;37(1):19-31.

37. Taylor TD, Klotz MW, Lawton RA. Titanium tattooing associated with zirconia implant abutments: a clinical report of two cases. Int J Oral Maxillofac Implants. 2014;29(4):958-60. 